\title{
SIKAP REMAJA DENGAN PEMANFAATAN PIK-R PADA REMAJA
}

\author{
Arum Dwi Anjani ${ }^{1 *}$, Beril Triana ${ }^{2}$ \\ 1,2Program Studi Kebidanan Fakultas Kedokteran Universitas Batam \\ *Korespondesi Email : arum.dwianjani05@univbatam.ac.id \\ ${ }^{2}$ Klinik Bidan Triana Beril Tanjung Balai Karimun
}

\section{ABSTRACT ATTITUDES OF ADOLESCENT USING PIK-R IN ADOLESCENTS}

Background The problem that stand out among the teenager is problem around Triad KKR (sexuality, HIV and AIDS also NAPZA) based on the visit record to PKPR, found that number of IMS incident to teenager rank first, that is around $50 \%$ from the total of counseling that done at 2009. Mention that the rampant cases happens because of prosmicuti that related to reproduction health for teenager.

Purpose to know the relation of teenager attitude with utilization of PIK - $R$ to teenager.

Methods use "cross sectional" approach. Research variabel consist of independiente variabel teenager attitude, dependent variabel utilization of PIK - R. Deep Hypothesis have a relate between attitude and utilization of pik $r$. research time was carried out for 6 month. Research are done at goverment high school 4 karimun. Population of this research is the teenager members of PIK $R$ grade 10 and 11 at goverment high school 4 karimun total of 36 teenager. The researcher use the technic of total sampling as sample of this research. Instrument use questionnaire. Analysis use chi square statistical test by using the score of significant 0,05 to see relation if the score $p<0.05$, so ho is rejected and ha.

Results showed that most of the respondents, namely 34 or $94.4 \%$ of respondents had a positive attitude and only 2 respondents or $5.6 \%$ of respondents had negative attitudes, of the 36 respondents, 34 people or $94.4 \%$ had positive attitudes and all of them (100\%) of them used PIK-R, the remaining 2 respondents or $5.6 \%$ of respondents had negative attitudes and in this attitude group all (100\%) did not take advantage of PIK-R $p$ value $=0.002$.

Conclusion there is a relation that si significant between teenager attitude and utilization od PIK-R. Advice for the teenager to be more active make use of the activity PIK-R by utilize the facility that is in the school

Suggestion To be more active in utilizing PIK-R activities by utilizing existing PIK-R facilities in schools

Keywords: Attitudes, Youth and Utilization of PIKR

\section{ABSTRAK}

Latar Belakang berbagai penelitian menunjukan bahwa remaja mempunyai permasalahan yang sangat kompleks seiring dengan masa transisi yang dialami remaja. Masalah yang menonjol dikalangan remaja yaitu permasalahan seputar TRIAD KRR (Seksualitas, HIV dan AIDS serta NAPZA). Berdasarkan catatan kunjungan ke PKPR, ditemukan bahwa angka kejadian IMS pada remaja menduduki urutan pertama, yaitu sekitar $50 \%$ dari total konseling yang dilakukan pada tahun 2009. Disebutkan bahwa maraknya kasus tersebut terjadi akibat pergaulan bebas yang terkait dengan kesehatan reproduksi pada remaja.

Tujuan untuk mengetahui hubungan sikap remaja dengan pemanfaatan PIK-R pada remaja.

Metode penelitian menggunakan pendekatan "Cross sectional". Variabel peneliti terdiri dari variabel independen sikap remaja, variabel dependen pemanfaatan PIK-R. Hipotesis dalam Ada hubungan antara sikap dengan pemanfaatan PIK-R. Waktu penelitian dilakukan selama 6 Bulan. Penelitian telah dilakukan di SMA Negeri 4 Karimun. Populasi pada penelitian ini adalah remaja anggota PIK-R Kelas X dan XI di SMA Negeri 4 Karimun pada sebanyak 36 orang. Sampel pada penelitian ini peneliti menggunakan teknik Total Sampling. Instrument menggunakan kuesioner. Analisis menggunakan uji statistik chi square dengan menggunakan taraf signifikan 0,05 untuk melihat hubungan, jika nilai $p \leq 0,05$ maka Ho ditolak dan $\mathrm{Ha}$.

Hasil Penelitian diperoleh sebagian besar responden yaitu sebanyak 34 atau $94,4 \%$ responden memiliki sikap positif dan hanya 2 responden atau 5,6\% responden memiliki sikap negatif, dari 36 responden, ada 34 orang atau $94,4 \%$ yang memiliki sikap positif dan semuanya (100\%) diantaranya memanfaatkan PIK-R selebihnya ada 2 responden atau $5,6 \%$ responden memiliki sikap negatif dan pada kelompok sikap ini seluruhnya $(100 \%)$ tidak memanfaatkan PIK-R $p$ value $=0,002$.

Kesimpulan ada hubungan yang signifikan antara sikap remaja dengan pemanfaatan PIK-R. 


\section{JKM (Jurnal Kebidanan Malahayati),Vol 7,No.2.April 2021, ISSN (Print) 2476-8944 ISSN (Online) 2579-762X, Hal 340-346}

Saran bagi remaja agar lebih aktif memanfaatkan kegiatan PIK-R melalui cara memanfaatkan fasilitas yang ada di sekolah.Saran Agar lebih aktif memanfaatkan kegiatan PIK-R melalui cara memanfaatkan fasilitas PIK-R yang ada di sekolah

Kata Kunci : Sikap, Remaja dan Pemanfaatan PIKR

\section{PENDAHULUAN}

Masa remaja adalah masa dimana seseorang mengalami suatu masa peralihan dari masa kanak-kanak ke masa dewasa. Dikatakan remaja apabila umur mereka mencapai kurang lebih sekitar 10-20 tahun dan masa remaja ini berlangsung kurang lebih selama 4 tahun. Saat masa tersebut, remaja akan mengalami kejadian penting dalam hidupnya seperti pertumbuhan badan yang cepat, timbulnya ciri-ciri kelamin sekunder, menstruasi, perubahan psikis (Prawirohardjo, 2008)

Menurut WHO, remaja adalah penduduk dalam rentang usia 10-19 tahun, pada periode ini terjadi pertumbuhan dan perkembangan yang pesat baik secara fisik, psikologis maupun intelektual. Sifat khas remaja mempunyai rasa keingintahuan yang besar, menyukai petualangan dan tantangan serta cenderung berani menanggung resiko atas perbuatannya tanpa didahului oleh pertimbangan yang matang. Didunia diperkirakan kelompok remaja berjumlah 1,2 milyar atau $18 \%$ dari jumlah penduduk dunia (WHO, 2014)

Kehidupan remaja merupakan kehidupan yang sangat menentukan bagi kehidupan masa depan mereka selanjutnya. Pada tahun 2016 jumlah remaja umur 10-24 tahun sangat besar yaitu sekitar 66,3 juta jiwa dari jumlah penduduk Indonesia sebanyak 258,7 juta jiwa sehingga satu diantara empat penduduk adalah remaja. Melihat jumlah yang sangat besar, maka remaja sebagai generasi penerus bangsa perlu dipersiapkan menjadi manusia yang sehat secara jasmani, rohani, mental dan spiritual (BKKBN, 2016)

Masa remaja adalah masa transisi yang ditandai oleh adanya perubahan fisik, emosi, dan psikis. (Sarwono, 2010). Dalam perkembangan emosi remaja memiliki rasa ingin tahu yang besar sehingga bermanifestasi menjadi suka mencobacoba hal baru, misalnya berpacaran dan melakukan aktivitas seksual yang pada akhirnya mengarah pada perilaku berisiko. Kondisi ini tidak lepas dari pengaruh lingkungan, di antaranya globalisasi informasi melalui media yang telah menyebabkan perubahan perilaku seksual remaja. Eksploitasi seksual dalam televisi, majalah, video klip, media online dan film banyak memengaruhi remaja melakukan aktivitas seks secara bebas. Pengumbaran adegan seks melalui tayangan media tersebut menimbulkan persepsi bahwa kegiatan seks bebas boleh dilakukan oleh siapapun dan dimanapun tanpa memandang sisi etika, terlebih remaja belum memiliki kematangan emosi.

Menurut (Desmita, 2011) masa remaja ditandai dengan sejumlah karakteristik penting yang meliputi pencapaian hubungan yang matang dengan teman sebaya, dapat menerima dan belajar peran sosial sebagai pria atau wanita dewasa yang dijunjung tinggi oleh masyarakat, menerima keadaan fisik dan mampu menggunakanya secara efektif, mencapai kemandirian emosional dari orang tua dan orang dewasa lainnya, memilih dan mempersiapkan karier dimasa depan sesuai dengan minat dan kemampuannya, mengembangkan sikap positif terhadap pernikahan hidup berkeluarga dan memiliki anak, mengembangkan keterampilan intelektual dan konsep-konsep yang diperlukan sebagai warga negara, mencapai tingkah laku yang bertanggung jawab secara sosial dan memperoleh seperangkat nilai dan sistem etika sebagai pedoman dalam bertingkah laku.

Berbagai penelitian menunjukan bahwa remaja mempunyai permasalahan yang sangat kompleks seiring dengan masa transisi yang dialami remaja. Masalah yang menonjol dikalangan remaja yaitu permasalahan seputar TRIAD KRR (Seksualitas, HIV dan AIDS serta NAPZA). Badan Narkotika Nasional menunjukkan bahwa jumlah pengguna Napza adalah 115.404. Dimana 51.986 dari total pengguna adalah mereka yang berusia remaja (usia 16-24 tahun ). Mereka yang pelajar sekolah berjumlah 5.484 dan mahasiswa berjumlah 4.055. Secara Komulatif jumlah kasus HIV sebesar 71.437 kasus. Sedangkan kasus AIDS sebesar 25.936 kasus. Dari jumlah kasus tersebut, $45,9 \%$ adalah kelompok usia 20-29 tahun (Kemenkes RI, 2011). Sedangkan berdasarkan penelitian dari Australian National University (ANU) dan Pusat Penelitian Kesehatan Universitas Indonesia tahun 2010 di Jakarta, Tangerang, dan Bekasi (JATABEK) dengan jumlah sampel 3006 responden (usia < 1724 tahun), menunjukkan bahwa $20,9 \%$ remaja mengalami kehamilan dan kelahiran sebelum menikah dan $38,7 \%$ remaja mengalami kehamilan sebelum menikah dan kelahiran setelah menikah. Dari data tersebut terdapat proporsi yang relatif 
tinggi pada remaja yang melakukan pernikahan disebabkan oleh kehamilan yang tidak diinginkan (BKKBN, 2015a)

Hasil (SDKI, 2007) menunjukkan bahwa pengetahuan remaja tentang kesehatan reproduksi remaja relatif masih rendah. Remaja perempuan yang tahu tentang kesehatan reproduksi sebanyak $32,3 \%$. Sedangkan remaja laki-laki yang mengetahui tentang kesehatan reproduksi remaja sebanyak 47,9\% (SDKI, 2007). Adapun faktor yang mempengaruhi rendahnya pengetahuan remaja tentang kesehatan reproduksi remaja adalah informasi dan sumber informasi yang diperoleh remaja. Informasi dapat diperoleh baik dari pendidikan formal maupun non formal yang memberikan pengaruh jangka pendek (imediatelmpact) sehingga menghasilkan perubahan atau peningkatan pengetahuan. Majunya teknologi akan tersedia bermacam-macam media massa yang dapat mempengaruhi pengetahuan masyarakat tentang inovasi baru. Dalam penyampaian informasi sebagai tugas pokoknya, media massa membawa pula pesanpesan yang berisi sugesti yang dapat mengarahkan opini seseorang (Notoatmodjo, 2007)

Program kesehatan reproduksi remaja diintegrasikan dalam program kesehatan remaja di Indonesia. Sejak tahun 2003, kementrian kesehatan telah mengembangkan model pelayanan kesehatan yang disebut dengan Pelayanan Kesehatan Peduli Remaja atau disingkat PKPR (Kemenkes, 2010) Kegiatan pelayanan kesehatan reproduksi remaja juga terdapat dalam program generasi berencana (Genre) yang diselenggarakan oleh Badan Kependudukan dan Keluarga Berencana (BKKBN). Program Genre dilaksanakan melalui pendekatan dari dua sisi yaitu pendekatan kepada remaja itu sendiri dan pendekatan pada keluarga yang memiliki keluarga. Pendekatan pada remaja dilakukan melalui pengembangan Pusat Informasi dan Konseling Remaja/PIK-R (BKKBN, 2015b)

Berdasarkan wawancara dengan pe-megang program pelayanan kesehatan peduli remaja (PKPR) di Puskesmas Buleleng, pe-laksanaan kegiatan PKPR dilakukan baik secara perorangan maupun berkelompok, melalui pemberian informasi dan edukasi, pelayanan klinis, konseling, pendidikan ketrampilan hi-dup sehat, peer konselor, dan pelayanan ruju- kan. Berdasarkan catatan kunjungan ke PKPR, ditemukan bahwa angka kejadian IMS pada remaja menduduki urutan pertama, yaitu sekitar $50 \%$ dari total konseling yang dilakukan pada tahun 2009. Disebutkan bahwa maraknya kasus tersebut terjadi akibat pergaulan bebas yang terkait dengan kesehatan reproduksi pada remaja. Terdapat berbagai faktor yang berpengaruh terhadap hal tersebut, antara lain factor biologi, psikologis dan perkembangan kognitif, aktivitas seksual, etika dan pelayanan kesehatan khusus remaja (Endarto, 2009)

PIK-R memiliki peranan yang penting dalam meneruskan informasi kesehatan utamanya kesehatan reproduksi di kalangan remaja. Hal ini bertujuan agar remaja mendapatkan informasi yang merata terkait dengan kesehatan reproduksinya. Dalam pengelolaan PIK-R terdapat batasan atau ruang lingkup materi yang berkaitan dengan pembelajaran dalam PIK-R

Menurut data BKKBN Kepulauan Riau Tahun 2017 ada 149 PIK-R yang sudah terbentuk di Kepulauam Riau. Dengan nilai pemanfaatan PIK-R tertinggi adalah Batam dan Bintan (100\%) sedangkan yang terendah kedua adalah Karimun $(56,7 \%)$ nomor 2 (dua) terendah setelah Anambas $(23,8 \%)$.

Di Kabupaten Karimun sendiri menurut dari Pemberdayaan Perempuan, KB dan Perlindungan Anak pada tahun 2017 sudah terdapat kelompok PIK-R, yaitu 18 (delapan belas) kelompok PIK-R yang ada dilingkungan sekolah. Dari 18 kelompok PIK-R ada 4 kelompok PIK-R yang aktif (PP, KB dan PA Kabupaten Karimun, 2017).

Berdasarkan studi pendahuluan yang dilakukan di SMA 4 Karimun,yang sudah memiliki PIK-R, dari 273 jumlah siswa kelas $X$ dan $X I$ yang telah mengikuti PIK-R adalah 30 orang remaja putri dan 6 orang remaja putra. Sedangkan hasil wawancara kepada 10 remaja, dan didapatkan hasil 5 remaja sama sekali tidak mengetahui tentang PIK-R, 3 remaja mengatakan sudah mengetahui dan mengerti tentang PIK-R tetapi merasa enggan untuk bergabung, dan 2 remaja mengatakan sudah mengetahui dan mengerti tentang PIK-R serta remaja tersebut sudah terlibat dalam PIK-R.

Penelitian ini memiliki tujuan untuk mengetahui hubungan sikap remaja dengan pemanfaatan PIK-R pada remaja.

\section{METODE PENELITIAN}

Peneliti menggunakan desain penelitian korelasi dengan pendekatan desain "Cross sectional". Dalam penelitian ini variabel yang diamati oleh peneliti terdiri dari variabel independen atau variabel bebas yaitu sikap remaja, sedangkan variabel dependen atau variabel terikat adalah pemanfaatan Pusat Informasi dan Konseling Kesehatan Reproduksi Remaja (PIK-R) pada remaja. Hipotesis dalam penelitian ini adalah Ada hubungan antara sikap dengan pemanfaatan pusat informasi dan konseling kesehatan reproduksi 


\section{JKM (Jurnal Kebidanan Malahayati),Vol 7,No.2.April 2021, \\ ISSN (Print) 2476-8944 ISSN (Online) 2579-762X, Hal 340-346}

remaja (PIK-R) pada remaja. Waktu penelitian dilakukan selama 6 Bulan. Penelitian telah dilakukan di SMA Negeri 4 Karimun. Populasi pada penelitian ini adalah remaja anggota PIK-R Kelas $X$ dan XI di SMA Negeri 4 Karimun sebanyak 36 orang. Sampel menggunakan teknik Total Sampling. Instrument yang digunakan kuesioner yang dilakukan secara terpimpin, yaitu berupa pertanyaan tertulis yang ditujukan kepada responden untuk dijawab. Analisis bivariat ini digunakan untuk mengetahui hubungan antara variabel dependen dan independen. Data disajikan dalam bentuk tabel silang selanjutnya dianalisis menggunakan uji statistik chi square dengan menggunakan taraf signifikan 0,05 untuk melihat hubungan antara sikap pada remaja dengan pemanfaatan PIK-R pada remaja jika nilai $p \leq 0,05$ maka Ho ditolak dan $\mathrm{Ha}$ diterima artinya ada hubungan antara sikap pada remaja dengan pemanfaatan PIK-R pada remaja, jika nilai $p>0,05$ maka Ho diterima artinya tidak ada hubungan antara sikap pada remaja dengan pemanfaatan PIK-R pada remaja.

\section{HASIL PENELITIAN}

Tabel 1.

Distribusi Frekuensi responden berdasarkan Sikap remaja

\begin{tabular}{ccc}
\hline Sikap Remaja & $\begin{array}{c}\text { Frekuensi } \\
\text { (n) }\end{array}$ & $\begin{array}{c}\text { Persentase } \\
(\%)\end{array}$ \\
\hline Negatif & 2 & 5,6 \\
Positif & 34 & 94,4 \\
\hline Total & 36 & 100 \\
\hline
\end{tabular}

Diketahui bahwa sebagian besar responden yaitu sebanyak 34 atau $94,4 \%$ responden memiliki sikap positif dan hanya 2 responden atau 5,6\% responden memiliki sikap negatif

Tabel 2.

Hubungan antara sikap remaja dengan pemanfaatan PIK-R

\begin{tabular}{cccccccc}
\hline \multirow{2}{*}{$\begin{array}{c}\text { Sikap } \\
\text { Remaja }\end{array}$} & \multicolumn{4}{c}{ Pemanfaatan PIK-R } & \multicolumn{2}{c}{ Total } & \multirow{2}{*}{$\boldsymbol{P}$ Value } \\
\cline { 2 - 6 } & \multicolumn{2}{c}{ Tidak memanfaatkan } & \multicolumn{2}{c}{ Memanfaatkan } & \multicolumn{2}{c}{} \\
\cline { 2 - 7 } & $\mathbf{n}$ & $\%$ & $\mathbf{n}$ & $\%$ & $\mathbf{N}$ & $\%$ & \\
\hline Negatif & 2 & 100 & 0 & 0 & 2 & 100 & \multirow{2}{*}{0,002} \\
Positif & 0 & 0 & 34 & 100 & 34 & 100 & \\
\hline \multicolumn{1}{c}{ Total } & 2 & 5,6 & 34 & 94,4 & 36 & 100 & \\
\hline
\end{tabular}

Diketahui dari 36 responden, ada 34 orang atau $94,4 \%$ yang memiliki sikap positif dan semuanya (100\%) diantaranya memanfaatkan PIK$R$ selebihnya ada 2 responden atau $5,6 \%$ responden memiliki sikap negatif dan pada kelompok sikap ini seluruhnya (100\%) tidak memanfaatkan PIK-R. Hasil uji chi square diperoleh $p$ value $=0,002$ artinya secara statistik ada hubungan yang signifikan antara sikap remaja dengan pemanfaatan PIK-R.

\section{PEMBAHASAN SIKAP}

Hasil penelitian mengenai sikap remaja tentang PIK-R menunjukkan hasil bahwa sebagian besar responden memiliki sikap positif tentang PIK$R$ yaitu sebanyak 34 responden atau $94,4 \%$.

Menurut (Dewi \& Kamidah, 2012) sikap dapat diposisikan sebagai hasil evaluasi terhadap obyek sikap yang diekspresikan ke dalam proses kognitif, afektif (emosi) dan perilaku. Dari definisidefinisi di atas menunjukkan bahwa secara garis besar sikap terdiri dari komponen kognitif (ide yang umumnya berkaitan dengan pembicaraan dan dipelajari), perilaku (cenderung mempengaruhi respon sesuai dan tidak sesuai) dan emosi (menyebabkan respon-respon yang konsisten). Menurut (Azwar, 1988) tingkatan sikap terdiri dari : menerima (Receiving), merespon (Responding), menghargai (Valuing), bertanggung jawab (responsible). Menurut (Azwar, 1988) faktor-faktor yang mempengaruhi sikap terhadap objek sikap antara lain: pengalaman pribadi, pengaruh orang lain yang dianggap penting, pengaruh kebudayaan, mdia massa, lembaga pendidikan dan lembaga agama, faktor emosional.

Menurut penelitian (Maolinda et al., 2012) tentang hubungan pengetahuan dengan sikap siswa terhadap pendidikan kesehatan reproduksi remaja di SMAN 1 Margahayu menunjukkan hasil bahwa sebagian besar remaja bersikap positif sebanyak $55 \%$ dan hanya $45 \%$ responden yang bersikap negatif.

Sejalan dengan hasil penelitian ini yang menunjukkan sebagian besar remaja memiliki sikap positif, hal ini disebabkan oleh pengetahuan atau pemahaman yang baik pada remaja SMAN 4 Tanjung Balai Karimun tentang PIK-R. Selain itu 
banyaknya jumlah remaja puteri yang menjadi anggota PIK-R di sekolah mencerminkan tingginya minat remaja putri untuk berkecimpung dalam aktifitas PIK-R serta dapat menjadi salah satu upaya promosi dan sosialisasi kegiatan PIK-R dikalangan remaja SMA, mengingat remaja putri lebih mampu dan memiliki kemampuan lebih baik dalam berkomunikasi dalam hal penyebarluasan informasi mengenai kesehatan reproduksi di kalangan remaja melalui kegiatan "curhat" di kalangan remaja putri pada umumnya. Namun demikian, sikap anggota PIK-R belum 100\% berada pada kategori sikap positif sehingga tetap dibutuhkan tindak lanjut dalam meningkatkan sikap anggota PIK-R terhadap keberadaan kegiatan PIK$R$ di sekolah seperti dibutuhkan trik untuki meningkatkan kegiatan PIK-R melalui kegiatan kerjasama antar ekskul misalnya ekskul Palang erah Remaja (PMR) dapat diintegrasikan dengan kegiatan PIK-R demikian halnya pada kegiatan ekskul lain dapat diintegrasikan dengan kegiatan PIK-R sehingga diharapkan mampu menumbuhkan sikap positif dalam diri remaja untuk memanfaatkan PIK-R di sekolahnya karena dalam satu wadah PIK$\mathrm{R}$ tidak hanya membahas mengenai masalah kesehatan reproduksi remaja saja namun banyak informasi bermanfaat lainnya yang terintegrasi pada kegiatan PIK-R seperti informasi mengenai peningkatan kualitas hidup remaja, bahaya narkoba dikalangan remaja serta informasi mengenai pernikahan usia remaja dan lain-lain. Selain itu dapat juga dilakukan kegiatan pertemuan rutin mingguan anggota PIK-R melalui kegiatan rekreasi bersama yang dikemas bersama kegiatan penyuluhan mengenai kesehatan reproduksi pada remaja yang dapat disampaikan langsung oleh instansi terkait seperti BKKBN atau pelayanan kesehatan seperti puskesmas yang terdapat di wilayah SMAN 4 Tanjung Balai Karimun.

\section{HUBUNGAN SIKAP DENGAN PEMANFAATAN PIK-R}

Hasil penelitian mengenai hubungan sikap remaja dengan pemanfaatan PIK-R di SMA Negeri 4 karimun Tahun 2018 menunjukkan hasil bahwa dari 36 responden, ada 34 orang atau $94,4 \%$ yang memiliki sikap positif dan semuanya (100\%) diantaranya memanfaatkan PIK-R selebihnya ada 2 responden atau $5,6 \%$ responden memiliki sikap negatif dan pada kelompok sikap ini seluruhnya $(100 \%)$ tidak memanfaatkan PIK-R. Hasil uji chi square diperoleh $p$ value $=0,002$ artinya secara statistik ada hubungan yang signifikan antara sikap remaja dengan pemanfaatan PIK-R.
Menurut (Azwar, 1988), tingkatan sikap terdiri dari : menerima (Receiving), merespon (Responding), menghargai (Valuing), bertanggung jawab (responsible). Menurut (Azwar, 1988) faktorfaktor yang mempengaruhi sikap terhadap objek sikap antara lain: pengalaman pribadi, pengaruh orang lain yang dianggap penting, pengaruh kebudayaan, media massa, lembaga pendidikan dan lembaga agama, faktor emosional. Dalam hal ini sikap yang dihubungkan dengan perilaku pemanfaatan PIK-R yang sejalan dengan teori Lawrence Green dalam (Notoatmodjo, 2007) terlihat bahwa pemanfaatan fasilitas PIK-R di sekolah dipengaruhi oleh 3 faktor utama yaitu faktor predisposisi (pengetahuan, sikap, keyakinan), faktor Faktor Pendukung adalah faktor yang mendukung atau memfasilitasi terjadinya perubahan perilaku misalnya fasilitas pelayanan kesehatan, pendidikan, dan informasi kesehatan. Faktor pendukung ini juga turut mempengaruhi pemanfaatan PIK-R. Seperti penelitian yang dilakukan oleh (Lucin \& Ismail, 2012) mengungkapkan bahwa siswa kurang memanfaatkan PIK-R disebabkan oleh fasilitas, metode, lingkungan yang kurang nyaman dan waktu untuk konseling yang kurang memadai serta faktor penguat dalam hal ini seperti dukungan dari anggota PIK-R itu sendiri.

Sejalan dengan penelitian sebelumnya telah dilakukan oleh (Kamau, 2006) dalam (Ningrum, 2014) di Kenya yang bertujuan untuk menentukan faktor-faktor yang mempengaruhi akses dan pemanfaatan pelayanan kesehatan reproduksi remaja di sekolah. Ditemukan bahwa akses pemanfaatan pelayanan kesehatan reproduksi oleh remaja masih rendah

Menurut penelitian (Rahayu, 2014) tentang faktor-faktor yang berhubungan dengan layanan pusat informasi dan konseling kesehatan reproduksi remaja kelurahan Jatingaleh kecamatan Candisari menunjukkan ada hubungan menunjukkan hasil bahwa ada hubungan antara sikap remaja terhadap layanan pusat informasi dan konseling kesehatan reproduksi remaja (PIK-R) dengan $p$ value 0,018 .

Menurut (Ningrum, 2014) dengan mengupayakan penyaringan edukasi dan pemahaman maka PIK-R bekerjasama dengan tenaga kesehatan dalam hai ini terdapat pada bidan sebagai sumber edukasi konseling, bergerak menjadi sumber yang benar terhadap remaja. Salah satu komponen program yang disusun oleh pemerintah adalah adanya pembinaan remaja oleh bidan di sekolah-sekolah sebagai pembina dan pendidik kesehatan reproduksi yang bekerjasama dengan pihak tenaga kesehatan lain dengan upaya terdapat pemahaman yang benar pada siswa dalam 


\section{JKM (Jurnal Kebidanan Malahayati),Vol 7,No.2.April 2021, \\ ISSN (Print) 2476-8944 ISSN (Online) 2579-762X, Hal 340-346}

sehat reproduksi sehingga terdapat karakter preventif (pencegahan).

Sejalan dengan hasil penelitian ini yang menunjukkan ada hubungan antara sikap dengan pemanfaatan PIK-R pada remaja di sekolah ditandai dengan $p$ value 0,002 . Terlihat pada penelitian ini sebagian besar remaja memiliki sikap positif sehingga banyak yang memanfaatkan PIK-R di sekolah namun sayangnya belum $100 \%$ anggota PIK-R memanfaatkan kegiatan PIK-R dengan baik. $\mathrm{Hal}$ ini disebabkan oleh pengetahuan atau pemahaman walaupun sebagian besar anggota PIK-R memiliki pengetahuan yang baik tentang PIK$R$ namun pada beberapa kesempatan ada beberapa anggota PIK-R yang absen dalam setiap pertemuan rutin PIK-R di sekolah, disebabkan oleh urusan pribadi atau kejenuhan mengingat pertemuan rutin mingguan anggota PIK-R hanya dilakukan dalam ruangan kelas di luar jam sekolah sehingga untuk mengatasi hal ini disarankan untuk memperkaya kegiatan PIK-R bagi setiap anggotanya, dimana kegiatan penyuluhan PIK-R bagi setiap anggota PIK-R dapat dilakukan pertemuan diluar sekolah, seperti di tempat wisata atau sambil mengunjungi instansi yang terintegrasi pada kegiatan PIK-R di sekolah. Mengingat kegiatan PIK-R ini terintegrasi dengan program DAFTAR PUSTAKA

Aini, N., Maternity, D., Wahyuni, E. S., Idjradinata, P. S., \& Kartasasmita, A. S. (2014). POLA ASUH ORANG TUA, USIA DAN JENIS KELAMIN SEBAGAI FAKTOR YANG BERHUBUNGAN DENGAN PERSEPSI REMAJA TENTANG PERILAKU SEKSUAL PRA-NIKAH DI KOTA BATAM. Jurnal Medika Malahayati, 1(1), 38-42.

Ariani, F., \& Aulia, D. L. N. (2021). ADIKSI PENGGUNAAN SMARTPHONE DENGAN KETERAMPILAN KOMUNIKASI INTERPERSONAL SISWA/I SMAN 8 KOTA BATAM. Zona Kebidanan: Program Studi Kebidanan Universitas Batam, 8(3).

Aulia, D. L. N., \& Tan, C. C. (2020). PERAN PIK-R DENGAN PERILAKU SEKS PRANIKAH PADA REMAJA. Jurnal Kebidanan Malahayati, 6(2), 249-254

Aulia, D. L. N., \& Antika, I. A. (2018). HUBUNGAN PENGETAHUAN REMAJA AWAL TENTANG PUBERTAS DENGAN SIKAP MENGHADAPI PERUBAHAN FISIK. Jurnal Kebidanan Malahayati, 4(4)

Aulia, D. L. N. (2017). HUBUNGAN PENGETAHUAN DENGAN PRILAKU REMAJA PUTRI DALAM MENGKONSUMSI TABLET BESI (FE) SELAMA MENSTRUASI. pemerintah dalam hal ini BKKBN dalam salah satu bentuk kegiatan GenRe yang bertujuan untuk menciptakan remaja indonesia yang sehat dan berprestasi serta menekan angka pernikahan dini pada usia remaja.

\section{KESIMPULAN}

Ada hubungan yang signifikan antara sikap remaja dengan pemanfaatan PIK-R ditandai dengan $p$ value $=0,002$

\section{SARAN}

Bagi Remaja

Agar lebih aktif memanfaatkan kegiatan PIK-R melalui cara memanfaatkan fasilitas PIK-R yang ada di sekolah dan tidak segan bertanya kepada guru BK jika membutuhkan konsultasi lebih lanjut. Diharapkan juga kepada anggota PIK-R untuk mengurangi absen dalam pertemuan rutin mingguan karena selalu ada informasi baru dan baik dalam setiap pertemuan rutin PIK-R di sekolah, bukan hanya terbatas tentang kesehatan namun dapat juga diisi dengan informasi mengenai bagaimana mengelola keuangan dikalangan remaja.

Jurnal Kebidanan Malahayati, 3(3)

Azwar, S. (1988). Sikap dan Perilaku Dalam: Sikap Manusia Teori dan Pengukurannya. Pustaka Pelajar.

https://scholar.google.co.id/scholar?hl=en\&as _sdt $=0,5 \&$ cluster $=1663707165103417062$

BKKBN. (2015a). Materi Pegangan Kader Tentang Bimbingan Dan Pembinaan Keluarga Remaja.

BKKBN. (2015b). Menyiapkan Generasi Emas.

BKKBN. (2016). Materi Promosi Dan Konseling Kesehatan Reproduksi.

Dainty Maternity, S. S. T., Keb, M., \& Anjani, A. D. (2018). ASUHAN KEBIDANAN NEONATUS, BAYI, BALITA, DAN ANAK PRASEKOLAH. Penerbit Andi.

Dainty Maternity, S. S. T., Keb, M., Putri, R. D., \& Aulia, D. L. N. (2017). Asuhan Kebidanan Komunitas. Penerbit Andi.

Desmita. (2011). Psikologi Perkembangan Peserta Didik. PT Remaja Rosdakarya.

Dewi, A. C., \& Kamidah. (2012). Hubungan Antara Pengetahuan lbu Tentang Kesehatan Reproduksi Remaja Dengan Upaya Mempersiapkan Masa Pubertas Pada Anak. GASTER, 9(2), 17-25. https://jurnal.aiskauniversity.ac.id/index.php/gaster/article/view/3 $6 / 33$ 
Endarto, D. (2009). Pengantar Geologi Dasar. Universitas Sebelas Maret. http://library.fis.uny.ac.id/opac/index.php?p=s how_detail\&id=2492\&keywords=

Herlin F, Zahroh S. Pengetahuan Pendidik Sebaya Mempengaruhi Pemberian Informasi KRR di Kabupaten Kulon Progo.2014. Naskah Publikasi: Jurnal Promosi Kesehatan Indonesia Vol.9/No.2/Agustus2014

Kamau, A. W. (2006). Factors Influencing Access And Utilisation Of Preventive Reproductive Health Services By Adolescents In Kenya. A Case Study Of Murang'a District. https://core.ac.uk/download/pdf/15979186.pdf

Karolina, S Davita. Hubungan Pengelolaan PIKKRR dengan Pemanfaatan Pusat Informasi dan Konseling Kesehatan Reproduksi Remaja (PIK-KRR) pada Siswa Kelas XI di MAN II. 2015.Naskah Publikasi; STIKES 'Aisyiyah; Yogyakarta

Kemenkes. (2010). Pelayanan Kesehatan Peduli Remaja (PKPR).

Lucin, Y., \& Ismail, D. (2012). Pengetahuan, Sikap Dan Perilaku Tentang Seks Pranikah Terhadap Pemanfaatan Pusat Informasi Konseling Kesehatan Reproduksi Remaja (Pik-Krr) Pada Remaja Di Kota Palangka Raya.

http://etd.repository.ugm.ac.id/home/detail_pe ncarian $/ 58040$

Maolinda, N., Sriati, A., \& Maryati, I. (2012). Hubungan Pengetahuan Dengan Sikap Siswa Terhadap Pendidikan Kesehatan Reproduksi Remaja. Student E-Journals, 1(1), 1-15. http://jurnal.unpad.ac.id/ejournal/article/view/6 $09 / 663$

Maternity, D. (2015). Pola Asuh Orang Tua, Usia Dan Jenis Kelamin Sebagai Faktor Yang Berhubungan Dengan Persepsi Remaja Tentang Perilaku Seksual Pra-Nikah Di Kota Batam. Jurnal Kebidanan Malahayati, 1(1).
Muadz, M. Masri, dkk. 2007. Kurikulum dan Model Pelatihan Pengelolaan Pusat Informasi dan Konseling Kesehatan Reproduksi Remaja (PIKKRR).Jakarta: BKKBN

Ningrum, N. P. (2014). Hubungan Sikap Terhadap Informasi Kesehatan Reproduksi Remaja (Krr) Dengan Pemanfaatan Pusat Informasi Dan Konseling Remaja (Pik-R) Pada Remaja. http://digilib.unisayogya.ac.id/1123/1/Naskah Publikasi Novia Prafita Ningrum 201310104346 DIV Kebidanan.pdf

Notoatmodjo, S. (2007). Promosi Kesehatan dan IImu Perilaku. Rineka Cipta.

Nunung D, Firman. Hubungan persepsi dengan peranan siswa dalam pelaksanaan kegiatan pusat informasi konseling kesehatan reproduksi remaja http://repository.unimus.ac.id 70 di SMP 2 Pariaman. 2013.Jurnal IImiah Konseling; http;//ejournal.unp.ac.id/indeks-php/konselor.

Prawirohardjo, S. (2008). IImu Kebidanan. PT Bina Pustaka.

Rahayu, Y. S. (2014). Faktor-Faktor Yang Berhubungan Dengan Pemanfaatan Layanan Pusat Informasi Dan Konseling Kesehatan Reproduksi Remaja (Pik-Krr). http://eprints.undip.ac.id/53489/1/5016.pdf Sarwono. (2010). Psikologi remaja. Rajawali Pers. SDKI. (2007). Survei demografi dan kesehatan Indonesia.

WHO. (2014). Maternal Mortality.

Widyana S, Tri S. Hubungan Karakteristik Remaja Dengan Pengetahuan Remaja Mengenai Kesehatan Reproduksi di Kota Cimahi.2015.Naskah Publikasi: Stikes A.Yani ; Cimahi. 